In his private engineering practice at Belfast, he carried out important work in hydraulic machinery for use at home and in foreign countries. $\mathrm{He}$ invented the inward flow vortex turbine, and even now there are men in Ulster who are willing to talk at great length about his troubles and successes with this turbine. There was no practical man, however clever, who did not at first ridicule the scientific young gentleman who proposed to replace an eighty foot wheel by a tiny turbine, whose wheel was less than a foot in diameter. He never in his life could have had a happier moment than that in which, surrounded by crowds of astonished rustics and practical engineers, he saw this tiny wheel in its very first trial, driving the machinery of a large mill. And now, wherever turbines are to be found all over the world, they are mostly "Thomson" turbines, made on the principles so clearly thought out and described by him, albeit they are known under many very different names. His notions on such subjects as strength of materials and the effect of initial strains in materials, although published forty-four years ago, have only lately become the notions of practical engineers. At that early date, his ideas on many of the applications of science in engineering were very clear and correct, and far in advance of his contemporaries. He is especially to be recognized for his services in practical hydrodynamics, a subject in which there has been a more misleading appearance of mathematical theory than in any other branch of engineering. To one of Thomson's pupils it is positively painful to take up any authoritative treatise on hydraulic machinery, for he knows that nearly every page of troublesome mathematical reasoning is based on some absurd assumption, and that James Thomson's few propositions are almost the only ones on which the engineer can rely. James Thomson seemed to fear the misuse by young engineers of the recognized mathematical methods of attacking physical problems. He, himself, when he used mathematical expressions, used them merely to put before others the results of his own method of reasoning. It expresses only a part of the truth to say that he thought about things geometrically rather than algebraically. $\mathrm{He}$ refrained from publication until his proof was perfect, and some of his pupils may feel sorry that they have not more faithfully followed their master's example. A study of his successive manuscript proofs of his law of flow of fluids from similar orifices would probably enable us to conceive of the habits of thought of the Greek geometers : every word and phrase is carefully selected, and considered time after time with a view to perfect accuracy. Such invention and such regard for perfection of detail were surely never combined before.

When any of his speculations has been once published in an authoritative text-book, it will be noticed that it appears in all text-books published subsequently; the melting point of ice, the triple point in water-stuff, the continuity in the steam water isothermal, the tears of strong wine, are a few examples. No doubt, as time goes on, text-book writers will find that he discovered other important things. $\mathrm{He}$ was such a very observant man that he often put forward his most important propositions when explaining phenomena that seemed utterly insignificant. Let the reader only think that what occurs in a wash-basin, or in a little rivulet near the sea, may be of great importance scientifically, and let him read again some of Thomson's insignificant-looking scattered papers, and he will find important propositions published which will not, perhaps, for some years yet, find their proper positions in the text-books.

Of the history of thermodynamics during the eventful years $1849-50$, who dares now to say anything? Nor can anyone now say anything about the great glacier dispute. One thing is certain, however, that James Thomson's discovery of the necessary lowering of the melting-point of ice with pressure, published on January
2,1849 , settled for ever the theory of the flow of glaciers. Joule's work was beginning to be known, but Thomson, in his proof, like Lord Kelvin in the well-known paper published on the same day, adopts Carnot's idea of the conservation of heat. A change in one expression, not essential to the proof itself, was all that was needed after the first and second laws of thermodynamics had been recognized. Of his various papers on hydrodynamics, capillarity, heat, light, and the states of matter, published since that time, we have not space to say more than that each of them made a substantial addition to our knowledge. His latest work, the Bakerian Lecture this year of the Royal Society, on "The Grand Currents of Atmospheric Circulation," is such a paper as we might expect from a man who had given more than thirty-five years of study to the subject, that subject being one which was peculiarly his own. It is possible that the practical engineer, judging from the title merely, may neglect to read a paper which is one of phenomenal importance to the engineer as well as to the physiographer.

He was a man of singular purity of mind and simplicity of character, very clear-sighted in all that pertained to moral right and wrong, and conscientious to a degree. In his presence one felt in a purer atmosphere, where mean things seemed impossible. No Professor was ever so willing to take trouble (not mere momentary trouble, but trouble of days and nights) in the interests of a student, but no Professor was ever so rigidly exact in giving certificates and testimonials. The present writer has talked often with his old pupils about him, but never met one of them, who, besides a great respect, had not also a genuine and kindly and pleasurable love for his old Professor, whose kindness and patience had been unfailing, and whose sympathy had many a time been extended to him. How useless it is to speak of the good done to the world by a man of his character. Every one of his pupils, in however small or great a degree, is extending the range of his influence.

\section{JEAN SERVAIS STAS}

THE regret expressed in the obituary notice of Jean Servais Stas, that we had not the exact words of his famous discourse delivered before the King of the Belgians, has attracted the attention of a correspondent, who has very courteously sent us the text of the speech.

It was delivered by J. S. Stas in his capacity of President of the Royal Academy of Sciences, and was addressed to the King at the New Year's reception, January I, I89r. We have much pleasure in laying a translation of it before our readers :-

$$
\text { "Sire, }
$$

"The Royal Academy of Science, Literature, and the Fine Arts expresses its sincere wishes for the happiness of your Majesty, and the prosperity of your reign.

"As the central organ of the intellectual movement of the country, the Academy seeks to comprise within its arms the most varied talents, and to remain always an adequate and living expression of the entire activity of the human mind.

"This is both its duty and the reason for its existence. "In the sphere of Literature and Art its voice is almost always safely guided by public opinion-a competent judge of works accessible to all.

"It is otherwise in the sphere of Science.

"The physical, mathematical, and natural sciences, and even the moral and political sciences, do not appeal in the same degree to public opinion. If their conquests radiate afar, if they incessantly modify the conditions of social existence, they themselves develop in restricted circles, and work out of sight and of knowledge of the multitude. 
"The Universities, Sire, in our country especially, are the principal foci of scientific life. There not only the men of science of the future are trained, but the present representatives of higher research work, create, and distinguish themselves. There also the Royal Academy by preference seeks its fellows to associate them in its task and to render it fruitful.

"Its mission cannot be divorced from that of the institutions for higher education, and their lustre and their decline are simultaneous.

"In the name of this great and twofold interest the President of the Royal Academy feels bound to call the attention of your Majesty to the mode of appointment to the professorial chairs in the State Universities.

"The method adopted is absolutely faulty, and it affords to Science none of those guarantees which she has a right to demand.

"The intensity of party strife has the effect of absorbing into its vortex even those acts of the public authorities which ought to be least open to its influence. In place of conferring the University chairs upon the most capable men as their rightful prerogative, with the sole thought of raising the level of studies and of enlarging the intellectual patrimony of mankind, we too often see the spirit of faction disposing of such positions arbitrarily, to the injury of the scientific spirit.

"An incompetent professor paralyzes for a quarter of a century, even if he does not kill, instruction in the department committed to him. An improper nominee is a denial of justice.

"The courts of law have been invested with the right of presentation to vacant judgeships; an analogous prerogative ought to be conferred on the faculties of the Universities. Their choice would then be dictated by considerations essentially scientific, and to this end the Royal Academy relies on the great influence of the King."

"The King," adds the Intépendance Belge, "did not accept this appeal to his influence, and the Ministers present bestowed black looks upon the President of the Academy."

This impressive discourse has its lessons for us also, as it emphasizes the necessity of conferring scientific appointments purely in accordance rebus gestis, and in consideration of the actual work done by the candidate.

W. C.

\section{NOTES}

The annual conversazione of the Royal Society will be held on Wednesday, June 15 .

AT the annual meeting for the election of Fellows, held on Thursday last, the Royal Society elected the fifteen candidates whose names, with the statement of their qualifications, we have already printed.

THE British Medical Association will hold its sixtieth annual meeting at Nottingham on July 26 , and the three following days. Mr. Joseph White, consulting surgeon of the Nottingham General Hospital, will preside. Addresses will be given, in medicine, by Prof. James Cumming, of Queen's College, Belfast ; in surgery, by Prof. W. H. Hingston, of Montreal; and in hacteriology, by Dr. G. Sims Woodhead, of the Research Laboratory of the Colleges of Physicians and Surgeons, England. The scientific work of the meeting will be done in ten sections.

At a meeting of the American Philosophical Society, Philadelphia, on May 20, it was decided that the one hundred and fiftieth anniversary of the foundation of the Society should be worthily celebrated in 1893 , and a committee was appointed to make the necessary arrangements.

No. I I 80 , vOL. 46 ]
THE Federated Institution of Mining Engineers held their general meeting in London on Thursday and Friday last. At the meeting on Thursday papers were read on "Gold Mining in New Zealand," by G. J. Binns, and on "Petroleum in Eastern Europe and the Method of Drilling for it," by A. W. Eastlake. Prof. T. E. Thorpe gave some practical demonstrations of the action of coal-dust when exploded with gas. The members visited the Electrical Exhibition at the Crystal Palace in the afternoon, and dined tngether at the Garden Hall in the evening. Among the papers read at the meeting on Friday were papers on "The Causes of Spontaneous Combustion of Coal and Prevention of Explosion on Ships," by M. V. Jones ; "A Safety cage for Mines and Hoists," by J. Whitelaw; "Winding by Water-balance at J' $n$ is Merthyr Colliery," by M. W. Davies ; and "Gold Milling," by W. F. Wilkinson.

THE Alciini Medal for Animal Electricity has been awarded to Dr. A. Waller, Lecturer on Physiology, St. Mary's Hospital Medical School, by the Bologna Academy of Sciences.

THE Council of the Institution of Electrical Engineers decided that the Salomons Scholarship of $£ 35$ should be given to a second year's student training to become an electrical engineer at either King's College, University College, the City and Guilds Central Institution, or the Finsbury Technical College. The first award has just been made to C. H. C. Woodhouse, Matriculated Student of the Central Institution, Associate of the Royal College of Science, and B.Sc. of the London University.

AT the annual meeting of the Institution of Civil Engineers Mr. Harrison Hayter was elected to act as President for the ensung year. The Vice-Presidents are Alfred Giles, Sir Robert Rawlinson, Sir Benjamin Baker, F.R.S, and Sir Jas. N. Douglass, F.R.S. The following are the other members of Council :-W. Anderson, F.R.S., J. Wolfe Barry, Alex, R. Binnie, E. A. Cowper, Sir Douglas Fox, J. C. Hawkshaw, Charles Hawksley, Sir Bradford Leslie, George Fosbery Lyster, James Mansergh, Sir Guildford L. Molesworth, W. H. Preece, F.R.S., Sir Edward J. Reed, F.R.S., William Shelford, and Francis W. Webb.

In the official abstract of the report of the Council of the Institution of Civil Engineers for the session 1891-92, it is stated that $j 9$ associate members had been transferred to the class of member, and that there had been elected 3 honorary members, 28 members, 324 associate members, and 7 associates, while 4 associate members had been restored to the register. These additions together amounted to 366 . After deducting I 45 names from deaths, resignations, and erasures, there was an increase of $22 \mathrm{I}$, bringing up the total number on the register to $537 \mathrm{I}$, as against $5 \times 50$ at the corresponding date last year. This enumeration was irrespective of the students, of whom 200 had been admitted during the year, as against 166 for the previous twelve months; but during this period, Io6 students had become associate members, and 140 had disappeared from the list, so that the number now on the books was only 868 , whereas last year the number was 9r4. Thus, including students, the total number on the books was now 6239 , as against 6064 twelve months ago. The following awards have been made to the authors of papers which have been discussed:-A George Stephenson Medal and a Telford Premium to Mr. Alex. R. Binnie; Telford Medals and Telford Premiums to Mr. A. P. Trotter and Mr. W. T. Douglass; and Telford Premiums to Messrs. H. Alfred Roech ling, A. H. Curtis, W. Airy, H. Gill, and Prof. W. C. Roberts-Austen. In respect of communications which have been deemed suitable for printing without being discussed, Telford Medals and Telford Premiums had been adjudged to 